\title{
TOWARDS LIFEWORLD-ORIENTED \\ INFORMATION SYSTEMS DEVELOPMENT
}

Andrew Basden

Salford Business School, University of Salford, Salford, M5 4WT, U.K., sbs@basden.demon.co.uk

\section{ABSTRACT}

Information systems development is human activity. It is the human aspects that are important in the success of ISD projects. That many are overlooked might help to explain why ISD projects fail. This paper argues that many methodologies and academic discussion of ISD take an approach that focuses on certain aspects while overlooking others, and that a more lifeworld-oriented approach would be beneficial. It examines the notion of lifeworld as it has developed in philosophy, showing how a lifeworld-oriented attitude makes us more sensitive to the wide range of human aspects. Making use of Dooyeweerd's philosophy in particular, this notion is then applied to ISD, to propose lifeworld-oriented ISD (LOISD). The lifeworld of the IS developer is revealed as four interwoven multi-aspectual human activities, which helps separate out diverse issues while retaining an holistic perspective. The challenge of the background nature of the lifeworld is met by reference to intuitive grasp of the kernel meaning of aspects, which enables cross-cultural understanding.

\section{Keywords}

Information systems development, lifeworld, aspects of diversity, everyday experience in ISD.

\section{INTRODUCTION}

Information systems (IS) fail far too often. Sometimes the IS never reaches the stage of use, because the IS development (ISD) project fails, or sometimes failure occurs once the IS is in use, in that it provides no real benefits or might even bring harm. In the latter case, ISD failed to anticipate the real needs and possible repercussions of use. How can ISD-related failures be prevented, or at least reduced in frequency?

\subsection{Attempts to Assist ISD Success}

To reduce failure rates in both the ISD process and in future use of the IS, many and varied software development methodologies have emerged, ranging from linear approaches derived from the Waterfall model (Royce, 1970) through iterative approaches such as Boehm's (1988) classic spiral model to the agile methodologies of today (Beck, 2000). Another attack on the problem has been to seek better data models and computer languages, from procedural to declarative languages and from database models like Chen's (1976) Entity Relationship Model and Codd's (1970) Relational Data Model, then object-oriented approaches (Booch, 1991), to more recent approaches like Design Patterns (Gamma, Helm, Johnson \& Vlissides, 1995). Yet another attack has been to focus on defining and clarifying the business or application problem and solution, such as with Checkland's (1999) Soft Systems Methodology.

Though Soft Systems Methodology been quite widely applied in professional practice, it has also been criticised. Bergvall-Kåreborn, Mirijamdotter \& Basden (2004) review some of its problems in practice - such as that it tends to generate statements of the status quo rather than stimulating new insights (which was its aim). The root of this seems to be its grounding in phenomenology, which Hirshheim, Klein \& Lyytinen (1995) and and Probert (1997) criticise and argue that it results in difficulty in addressing power relations and other distortions in the communicative process 
during analysis, possible misuse by one group at the expense of another, and epistemological reductionism. Instead of grounding a methodology in phenomenology, Hirschheim \& Klein (1994) advocate grounding ISD in the critical notion of emancipation. Problems with their proposal include that emancipation is not well defined, and that, though emancipation is one important factor in ISD, there is much in ISD that cannot be appropriately thought about in terms of emancipation.

A plethora of IS methodologies and approaches have been proposed, yet the problem of failed or inappropriate ISD and IS stubbornly remains. In 1994 Jayaratna estimated there were around 1000 extant ISD methodologies (cited by Iivari, Hirschheim \& Klein, 1998), most of which are not making any impact on practice.

The IS research literature tries to make some sense of this by trying to generalise. For example, Kautz, Madson \& Nørbjerg (2007a) discuss 'persistent problems' in ISD, which they identify as organisation and specialisation of diversity, acquisition and negotiation of knowledge and perception and establishment of structure. They argue that neither changes in information technologies and applications, nor the move from traditional to agile techniques, have significantly changed the underlying challenging characteristics of ISD. In response to criticism, Kautz, Madson \& Nørbjerg (2007b) admit that they consider only a limited class of IS (websites). But there is a more serious issue here: they presuppose that diversity should be 'reduced', and that the only knowledge that is of interest has been "acquired" and "negotiated". Both presuppositions may be questioned: diversity might be welcomed and taken-for-granted knowledge often plays a role in actual ISD.

Iivari, Hirschheim \& Klein (1998) have suggested that instead of looking at ISD methodologies (ISDMs) it is useful to abstract from these and look at ISD approaches (ISDAs), to analyse the broad types of approach in the hope of being able to engage in 'methodology engineering'. Whereas ISDMs may be evaluated according to their impact, this does not allow navigation through the "methodology jungle", and study of ISDAs, which are general types of ISDM, separates the 'essentials' from the 'accidentals'. Of five ISDAs, which they call Interactionist, Speech-Act Based, Soft Systems Methodology, Trade Unionist and Professional Work Practices, they examine the ontological, epistemological, methodological and ethical assumptions. This systematises the jungle so that new types of ISDA may be considered. While study of extant ISDMs looks backward to the past, study of ISDAs can chart a course into the future. This is the approach taken here, but this paper does not follow Iivari et al.'s approach because it is not entirely appropriate.

On the one hand, as they acknowledge, their analysis was of what has been written about ISD methodology from the point of view of IS research rather than of actual practice. It is perhaps as a result of this that they propose the following as a way ahead:

"Concrete ISDMs as instances of ISDAs have various 'sediments' in terms of methods and tools that are not necessarily essential for the ISDA. After purifying them of such inessential sediments, and abstracting them to the level of ISDAs, the generation of an integrated ISDM could take place in a much more structured and elegant way."

While some 'sediments' might be 'accidentals' others are often the very things that determine the quality of an ISDM in real-life ISD. They range from small aspects of everyday human living, such as Wenger (1998) discusses and illustrates in relation to Communities of Practice, to major issues that occupy whole fields of research, such as software engineering and data modelling. While such issues should never dominate ISD, they are nevertheless essential components of ISD, and it is surprising to find no mention of them.

The reason for this might be found in another limitation they acknowledge: they base their analysis on Burrell \& Morgan's (1979) model of sociological paradigms, which sets objectivism over against subjectivism and order or consensus over against conflict. As a result, most of their discussion takes on a dualistic nature, even though they weaken it a little to allow opposing poles to coexist. The ontological discussion is about how each approach views data/information (as either descriptive or constitutive), information systems (as either social or technical), human beings (as either determined or voluntaristic), technology (as either determined or a matter of human choice) and organisations (as either structural or interactional). Epistemology is discussed in terms of being either positivist or antipositivist (interpretivist or critical). Ethics covers the role of IS science, which is conceived of as either a means to an 
end or as (critical) interpretation, and the value of IS research, which takes a more pluralistic than dualistic view. The value of IS research to each approach is largely determined by what the approach deems important and meaningful; the Interactionist approach focuses on the social aspect, the Speech-Act approach on the communicational aspect, Soft Systems Methodology on problem-solving and learning, the Trades Union approach on justice for workers and their interests, and the Professional Work Practices approach on professional management. Methodology refers not to ISD methodology but to IS research methodology, and their discussion of this is also pluralistic, but merely enumerates methodologies made use of in the past.

The prevalence of dualistic views seems problematic when compared with everyday reality of ISD. For example, human beings are more than just deterministic or voluntaristic, they are self-giving or selfish, just or unjust, frugal or wasteful, friendly or hostile, and many more. That everyday experience escapes the confines of the dualisms may be seen clearly in Wenger's (1998) detailed vignettes of IS use, but the author knows of no such detailed description of the everyday experience of ISD. So he presents the following case study of his own actual experience of one ISD project.

\subsection{A Case Study of Everyday Experience of ISD}

Research in ISD (or most other fields) is permeated with a tendency to focus on certain issues at the expense of others because it is based on theories or assumptions about what is important and how the world is shaped, leaving other issues unaddressed which are deemed unimportant ('sediments'). Column 1 of Table 1 below lists the main issues the discussion above cited. To be able to see the other issues that are important in real-life ISD we cannot presume to rely on the IS research literature as Iivari et al. (1998) did but must turn to the data of everyday experience.

For this reason, an example will be given of ISD in which this author was involved. Though some time ago (19861987), he still remembers very well the kinds of issues that he found important. Some of those that are seldom addressed in the IS research literature even today will be emphasised here. They are summarised in column 2 of Table 1. For more complete explanation than is given in the following, the reader is directed to Basden, Watson \& Brandon (1995).

The author was in a team building what became known as Elsie (Brandon, Basden, Hamilton \& Stockley, 1988), an expert system designed to assist quantity surveyors when taking a lead in construction projects in the UK (that is, before any architect had designed the building). The type of building was offices. Elsie proved to be a 'success', a study of its use being discussed in chapter IV of Basden (2008). Part of its success was due to the involvement of the Royal Institution of Chartered Surveyors, who bestowed credibility. This is an example of an issue often ignored in ISD literature.

Elsie comprised four modules, the purpose of which was to assist the users (quantity surveyors) in setting a budget, gauging project timescale, recommending a procurement method, and assessing long-term financial performance of the building. This author was the senior knowledge engineer and acted as mentor to the others. It was important that the other team members did not feel daunted and could develop their expertise in knowledge engineering with dignity - a second oft-ignored issue.

Elsie was developed over 30 months using a combination of iterative and linear approaches and intensive engagement with a variety of stakeholders, after which it was not only useful and usable but also 'trustable' and 'saleable'. Trustable meant it would not let the user down (by giving misleading or erroneous results) even in exceptional conditions. Saleable (psychologically as well as financially) meant that Elsie was made attractive so that it would be taken up by all those - and only those - who would benefit from using it but did not yet realise they might do so (notice this has an ethical component that overrides sales maximisation). At the time, combining iterative with linear approaches, participative development, and focusing on both usefulness and usability were rare, but they now occupy the ISD literature. However, the importance of trustability and saleability of the kind meant here is still not given due attention.

During the project, the author was assigned to developing the most complex module, budget-setting. He undertook knowledge acquisition interviews with six partner-level surveryors, who acted as domain experts, to elicit expert knowledge of how they would set budgets for new office developments. This knowledge included not only that which 
applies to most projects but also rare exceptions. There were several issues here that are seldom discussed in the IS literature. The knowledge was highly diverse, ranging over physical aspects of foundations, building shape, movement around building, health, functional quality, provision for technology, flexibility, cultural expectations, aesthetics of materials, legal issues and so on. Much of it was not readily explainable (tacit) and was probed by separating the problem-solving and contextual knowledge from underlying understanding, however informal the latter might be (Attarwala \& Basden, 1985). It was important to develop and maintain close relationships with these experts, built on trust and mutual respect, because the knowledge elicited was what gave them their dignity as experts. When two experts disagreed, it was important to ensure it did not become a conflict, and especially that neither felt they had 'won' or 'lost', but use the disagreement as a valuable source of knowledge. The issues of tacit knowledge and conflict are now discussed in the IS literature, but not in the way addressed in the project.

These experts also conveyed what was needed from a user's point of view, which indicated what 'frills' (as we knowledge engineers tended to call them at the time) would be useful - such as good, concise explanations of results, ability to override the reasoning with one's own values for such things as the quality level or the cost of bricks, ability to change inputs, and, crucially, ability to save current state of model for later. The author learned that it is such frills that are important in everyday use rather than more academically noteworthy attributes like knowledge completeness and Bayesian algorithms. An attitude of being willing to learn was vital here, informed by an attitude of being willing to expend oneself in giving more than is strictly necessary, combined with a certain creativity.

The potential users would change their minds about what was wanted. Though this was considered a problem in ISD at the time, the author believed differently: mind-change was an opportunity to probe and explore what would be truly useful. This came from a listening attitude coupled with employing common sense that was both critical and generous, putting oneself in the shoes of the other, and aiming for real-life use rather than mere delivery of an artifact.

The author was also involved in programming, developing algorithms not available in the knowledge representation system. This was always undertaken with an awareness of wider issues, not only of the application domain, but also of being 'true' to the nature of the reality being programmed. The author learned by experience not to cut corners nor simplify models!

A study of Elsie in use a few years later (Castell, Basden, Erdos, Barrows \& Brandon, 1992) revealed many interesting findings, including that Elsie changed the way the surveyors worked in ways that were unexpected but which were discovered by the users themselves. See chapter IV of Basden (2008) for details. Of particularly interest, in view of the prevalence of Foucauldian power-knowledge perspectives, was the replacement of a novice-expert relationship with that of two partners working towards a shared goal, in which the apparent loss of power was welcomed by both parties. Unexpected and indirect impacts of IS use are issues still not adequately addressed in ISD literature.

\subsection{The Need for Lifeworld-orientated ISD (LOISD)}

The Elsie case reveals a wide range of issues that could be important to the success of ISD projects but which are seldom, if ever, given adequate attention in the ISD research literature nor even in extant methodologies (though agile methods might address some of them). Doubtless other experience can bring up many more.

Table 1. Comparison of issues discussed and overlooked in ISD literature

\begin{tabular}{||l|l|}
\hline \multicolumn{1}{|c|}{ Issues Addressed in ISD Literature } & \multicolumn{1}{|c|}{ Additional Issues Important in Elsie } \\
\hline $\begin{array}{l}\text { ISD methodology: linear v. iterative, and combining both; agile } \\
\text { approaches }\end{array}$ & $\begin{array}{l}\text { Bestowing credibility on project. } \\
\text { Dignity of all team members. } \\
\text { Team members given space to develop } \\
\text { Data models: procedural v. declarative; entity-relationship v. } \\
\text { relational v. object-oriented; } \\
\text { Defining and clarifying business problem: hard v. soft v. critical } \\
\text { systems thinking }\end{array}$ \\
$\begin{array}{l}\text { Trustability: knowledge in IS will not let users } \\
\text { down even in exceptional condition. } \\
\text { Saleability: attract those who would benefit } \\
\text { but do not yet realise they might. } \\
\text { Ethical aspect overrides sales maximisation. }\end{array}$ \\
\hline
\end{tabular}


- Diversity to be reduced by organisation and specialisation

- Knowledge to be acquired and negotiated

- Structure to be perceived and established

Assumptions of ISD Approaches:

- Data/information as descriptive v. constitutive

- IS as technical v. social systems

- Human beings as determined v. voluntaristic

- Technology as determining v. human choice

- Organisations as structural v. interactional

- Epistemology as positivist v. anti-positivist

- Role of IS science as means to end v. interpretation

- Value of IS research: to assist organisations, communication, problem-solving, justice (interests), management (professionalism)

- Research methodology: case studies, conceptual development, formal analysis, technical development, action research
Diversity of knowledge to be encapsulated.

Disclosing domain understanding by

separating out problem-solving contextual knowledge.

Trust and mutual respect in relationships with domain experts.

Maintaining dignity of all who disagree with

each other.

'Frills': features important in everyday use but not worth reporting in academic papers.

Attitude in team: willing to learn, to expend oneself on behalf of others.

Users changing their minds as a source of

valuable knowledge.

A listening attitude coupled with common sense, putting oneself in shoes of other.

Criticality must be generous, not destructive.

Importance of aiming for beneficial real-life

use rather than mere delivery or sale of IS.

Giving domain knowledge its due; no cutting corners.

Unexpected and indirect repercussions of use.

Build so stakeholders can discover their own ways of working.

Paradox: loss of power welcomed.

It may be seen that many of the issues that made Elsie ISD successful are those found in everyday life. Many are to do with such things as attitude, which has until now been difficult to discuss in the IS literature because very few conceptual frameworks are available within which to make sense of it.

The central question this paper addresses is: How can we ensure that everyday issues are given the attention they deserve in both ISD research and ISD practice?

This suggests the need for a new approach rather than merely a new methodology (in Iivari et al.'s (1998) terms, new ISDA rather than ISDM), which embodies a new set of philosophical assumptions. This paper advocates a 'lifeworld' approach. The lifeworld may be defined loosely as that shared background knowledge on which we rely in everyday life (which includes both home and professional life and, particularly for this paper, ISD). It thus has close links with everyday activity itself, and therefore an understanding of the lifeworld might enable us to understand the 'real world' issues of ISD without treating them as mere 'sediments'.

It was noted that most of Iivari et al.'s analysis of what may be assumed is guided by a dualistic view. Everyday experience of ISD itself transcends these dualistic views and presents us with phenomena that cannot be neatly squeezed into their mould, even though, by convention, we might import them into professional ISD practice. It is not that the dualisms (such as the deterministic-voluntaristic dimension with which they view human beings) are wrong, but that they are too restrictive.

To answer the central question of this paper we must reflect of the very nature of the lifeworld and everyday experience. So section 2 builds up a picture of the lifeworld and everyday life by briefly reviewing what philosophers have said about the lifeworld and everyday life. The philosophy of Dooyeweerd (1955/1984) is particularly useful here. Section 3 applies this picture to ISD to propose 'lifeworld-orientated ISD' (LOISD). Section 4 concludes with discussion. 


\section{LIFEWORLD}

It was Husserl (1954/1970) who first used the term, 'life-world', when arguing that European sciences were in crisis. Science generates 'worlds' of knowledge, such as those of mathematics, geometry, physics, psychology, sociology, but there is a considerable amount of other knowledge by which we live our everyday lives - the 'life-world'. He argued that the process of doing science necessarily presupposed the life-world, in that many things done in science were only meaningful and justified by reference to the life-world. The long-assumed 'objectivity' of science was shown to rest on intersubjective foundations.

Since then other thinkers have extended the notion of lifeworld (now spelled without hyphen) far beyond Husserl's original use, to refer to the shared knowledge that we take for granted in everyday life, and by which everyday life functions smoothly. Some have used other names, including 'natural', 'everyday', 'self-evident', 'pre-theoretical' and 'naïve' (without negative connotations); the opposite is 'theorizing' or 'theoretical'.

\subsection{Attitudes: Lifeworld and Theorizing}

The terms 'everyday' and 'lifeworld' refer not so much to situations or spheres of life as to an attitude we take to them, be they home life, work or even the activity of scientific research. In a lifeworld (or everyday, pre-theoretical, naïve) attitude we take things "as they give themselves to us" (Husserl 1954/1970,p.156). Husserl proposed a 'principle of principles', that we should let things present themselves to us, rather than approaching them with $a$ priori theoretical constructs, which is the theorizing or theoretical attitude. Theories can be very useful (how, is discussed below) but the danger with a theoretical attitude is that it narrows the gaze onto certain factors so that other factors or aspects are overlooked and ignored.

In ISD prior theoretical constructs may be seen expressed in the type of development methodology adopted (e.g. linear or iterative) which in turn embodies presuppositions about what is meaningful and important (e.g. control of deadlines and resources, or user participation); other things, some illustrated by the Elsie case, are ignored. The data model adopted expresses theoretical constructs about on what basis the world to be modelled can be represented in symbols (e.g. mathematical tuples if relational model is adopted). ISD research also brings prior theoretical constructs. Kautz et al. (2007a) bring the theory that all that is important may be categorised into diversity, knowledge and structure, which embody the presuppositions that diversity is to be reduced and only explicit knowledge is important. Prior theoretical constructs in Iivari et al. (1998) include the components into which ontology and ethics are divided (including information, IS, humans, technology and organisations, but not, for example, the wider world or the nature of diversity) and the issues they discuss within each (which are mainly dualistic and thus, as we have seen, limiting). Each of these constitutes a theory about what is important and, therefore, what is less important, which they call 'sediments'. Prior theoretical constructs brought to ISD practice become troublesome when adherence to the methodology or data model is rigid. Prior theories brought to bear on IS research become troublesome when they restrict what is deemed worthy of research.

A lifeworld attitude might help to avoid this danger. If we are to move towards LOISD we need to understand the nature and characteristics of the lifeworld.

How may we understand the lifeworld? If we take a theoretical attitude to understanding the lifeworld, such as approaching it with the prior constructs of psychology, sociology or a prior perspective like functionalism (as Dewey's pragmatism does) then we fail to take the lifeworld as it presents itself to us. It is preferable to take a lifeworld attitude to understanding both the lifeworld and theoretical thought.

The Dutch philosopher, Dooyeweerd (1955/1984), is one thinker who attempted this. He began his magnum opus (1955/1984) with

"If I consider reality as it is given in the naïve pre-theoretical experience, ..." (Vol. I, p.3)

Pieces of his thought will be employed, along with that of others, to draw together some characteristics of everyday life and lifeworld, which differentiate a lifeworld or everyday attitude from a theorizing one. (For a systematic 
introduction to this little-known philosopher see Clouser (2005) or Basden (2008).)

\subsection{Diversity of Everyday Life and Lifeworld}

Dooyeweerd continued (1955/1984,I,p.3):

"... and then confront it with a theoretical analysis through which reality appears to split up into various modal aspects, then the first thing that strikes me, is the original indissoluble interrelation among these aspects ... A indissoluble inner coherence binds the numerical to the spatial aspect, the latter to the aspect of mathematical movement, the aspect of movement to that of physical energy, which itself is the necessary basis of the aspect of organic life. The aspect of organic life has an inner connection with that of psychical feeling, the latter refers in its logical anticipation (the feeling of logical correctness or incorrectness) to the analytical-logical aspect. This in turn is connected with the historical, the linguistic, the aspect of social intercourse, the economic, the aesthetic, the jural, the moral aspects and that of faith. In this inter-modal cosmic coherence no single aspect stands by itself; every-one refers within and beyond itself to all the others."

Dooyeweerd is here suggesting three things that most immediately present themselves to us. First, there is diversity. Second, to be aware of this we "split up" reality. Third, despite being "split up" by us the diversity coheres. It is only later that he attempts to discuss the nature of the diversity, of theoretical analysis and of coherence philosophically. What was key to his approach and makes it fruitful here is that he focused first not on diversity of things or occurrences (the 'what' of reality) but on diversity of ways in which the world can be and occur (the 'how').

Dooyeweerd is not alone in drawing attention to such diversity; for example Gadamer referred to a "wealth of modes" (1977,p.191) and, as has already been noted, Kautz et al. (2007a) sees diversity as a challenge for ISD. Reflecting on diversity with a lifeworld attitude involves distinguishing the aspects of what is concretely experienced. So thinkers differentiate aspects from each other, resulting in suites of aspects (or 'levels', 'strata') that range from formal ontologies (Bunge, 1979; Hartmann, 1952), through proposals for action types (Habermas, 1986) and Maslow's (1943) famous set of needs, to informal, alliterative lists of factors to be taken into account, such as Checkland's (1999) efficiency, effectiveness, efficacy, ethicality and elegance.

The relevance to ISD is the diversity of aspects of the human activities that constitute ISD and the coherence of the ISD project. It is useful to select a suite of aspects to guide our thinking and though we could select any of the above, we will employ Dooyeweerd's suite here not only because it is more comprehensive than most others, but because Dooyeweerd provided a more penetrating analysis of diversity, 'splitting-up' and coherence than most others have done. His suite is also more directly linked to everyday experience; some of the others were devised in relation to scientific conceptualization or with specific focus. Moreover, use of some suites might denature ISD. For example, employing Maslow's (1943) suite of needs would redefine ISD as an exercise in meeting the personal needs of individuals, rather than one of producing beneficial information systems.

Dooyeweerd's list cited above, though extensively discussed, is left only loosely defined in (1955/1984), partly because he maintained:

"In fact the system of the law-spheres designed by us can never lay claim to material completion. A more penetrating examination may at any time bring new modal aspects of reality to the light not yet perceived before. And the discovery of new law-spheres will always require a revision and further development of our modal analyses." (1955/1984,II,p.556)

That Dooyeweerd sometimes called aspects "law spheres", is because of his exploration of what aspects are. Each aspect is a way in which things can be meaningful (a sphere of meaning), a mode of being, a mode of functioning, a basic kind of property, a way of relating, a way in which things make sense (rationality), a kind of normativity (good and bad), and a kind of possibility for the future; see Basden (2008) for explanation of these. In this article the terms 'sphere of meaning', 'sphere of law' and 'aspect' will be used interchangeably, depending on what is being emphasised. 
According to Dooyeweerd, all things exhibit all aspects. So, as discussed later, ISD exhibits logical thought, history, language, social relationships, resources, legal issues, and so on.

\subsection{Use of Theory in Everyday Living}

If we accept Husserl's 'principle of principles', that we should not come with a priori theory, is it valid to make use of theory in ISD? Dooyeweerd (1955/1984,III,p.31) argued that "Naïve experience may be deepened through ... scientific knowledge, but cannot be destroyed by it." Theory may be brought in as long as it deepens without narrowing or causing undue distortion, and this is possible if we understand what lies at the root of the theoretical attitude.

Using transcendental critique, Dooyeweerd (1955/1984) argued that theoretical thinking necessarily pulls aspects apart (an extreme form of 'split up'), disrupting our view of their mutual interweaving, and Clouser (2005) explains this as high levels of abstraction of aspects away from reality, so that we focus exclusively on one aspect and study its laws without regard to its relationship with others. This generates theory, but to apply that theory requires re-integration, and that is a pre-theoretical act, presupposing human activity (lifeworld). Dooyeweerd and Clouser both argue that this grounds all theory-making in presuppositions that are religious in nature, so no theory can ever be neutral ('objective'), nor can it have any ultimate authority in itself. Because of its abstracted focus on one aspect, theoretical knowledge is likely to be inferior, not superior, to lifeworld knowledge.

There are two mitigations. One is that the aspects actually remain interwoven even when supposedly pulled apart, so we can always look for inter-aspect relationships, especially those of dependency and analogy (Basden 2008,p.71-72). The other is what Clouser calls lower abstraction, in which we are aware of the distinctions among aspects (e.g. the beauty vs. the cost of a rose) but do not abstract them away from the types of things that exhibit them.

\subsection{Lifeworld as Background}

The lifeworld attitude therefore eschews this pulling-apart of aspects. Other philosophers have thrown light on this. Heidegger (1927/1962) emphasised that the human being is immersed in the world, 'thrown' into it, and that is the lifeworld attitude, prior to splitting up reality. In everyday life we "live within" the world, so the knowledge of it that we make use of and rely on as we do so (viz. the lifeworld) must have a background character. "To live is always to live-in-certainty-of-the-world" wrote Husserl (1954/1970,p.142); in everyday living we place reliance on our lifeworld knowledge. To Husserl, the lifeworld is intuitive knowledge, 'pregiven', taken for granted (1954/1970,p.109). "By this taken-for-grantedness," say Schutz and Luckmann (1973,p.3-4), who developed his thought, "we designate everything which we experience as unquestionable". It has a 'tacit dimension' (Polanyi, 1967).

In a theoretical attitude, by contrast, we adopt a role of detached observers of the world, distancing ourselves from what is known, questioning what is taken for granted and trying to make aspects explicit. As a result, "The lifeworld ... dissolves ... before our eyes as soon as we try to take it up piece by piece," (Habermas, in Honneth, Knodler-Bunte and Windmann 1981,p.16).

The challenge is to minimise such distortion and the 'dissolving' of the lifeworld even though in ISD we must sometimes "take it up piece by piece". ISD involves both splitting the world up conceptually while at the same time engaging with it. How LOISD allows these to work in harmony, abating the detachment, is discussed later.

\subsection{Meaning and Normativity}

What is it that is taken for granted? Some of our background knowledge is of relational facts (for example, that programs need testing). A considerable amount of the lifeworld, however, is meaning (for example, what is important in testing) and norms (what we conceive as good and bad testing). Husserl's main concern, a 'crisis' in the European sciences, was loss of meaning and of "norms upon which man relies" (1954/1970, p.6-7). Habermas (1987) too acknowledged the lifeworld's meaning and normativity, though his concern was apparent loss of meaning in modern 
life in general.

Modern thinking has fundamental problems with meaning and normativity because Hume and Kant divorced them from existence (or process), and since that time much Western thinking has presupposed that 'facts' may be studied apart from 'values'. Ethics is relegated to something personal and optional. But the lifeworld knows nothing of the supposed divorce. Husserl sought "truths that are destined to be norms" (1954/1970,p.303), for example "the genuine judge, true honor, true courage and justice" - though it is debated whether he found a way to them. Dooyeweerd, however, might have found a way, because he rejected the Kantian-Humean presuppositions and grounded existence in meaning and law (1955/1984,I,p.4): to be a judge, qua judge, cannot be divorced from the normative notion of justice. However, he sharply differentiated between deep normativity, which transcends us, and norms that are concrete expressions of this, which are usually socially constructed.

\subsection{The Social Aspect of the Lifeworld}

The lifeworld is shared with others: when "thinking together, valuing, planning, acting together" (Husserl 1954/1970,p.109), we cannot do so successfully unless what is meaningful and normative to one is so to others in largely the same way. The lifeworld has an important social aspect and a strong (though weakly-understood) link with culture and world-view.

This makes language an important issue, as stressed by Hirschhein \& Klein (1994). Shared meanings enable us to understand what the other is saying, and language enables shared meanings and norms to develop. Habermas (1987) argued that this occurs when we critique the truthfulness, sincerity or appropriateness of each others' statements.

There are "highly different lifeworlds in which highly different things pass as unquestioningly self-evident" (Gadamer 1977,p.189) - e.g. those of engineers and judges, right- and left-wingers, adults and children, IS developers, domain experts and users. A person will live in several lifeworlds (a judge may be a left-winger), and some overlap. Some encompass others, e.g. left- and right-wing are mainly within the lifeworld of the Western world-view.

As human beings function well - for example in the domain of application of an IS - they do so with a background shared understanding of what is meaningful and important. This includes knowledge and experience of many meaningful things, norms, rationalities, happenings past and present, and future possibilities, including such things as how the domain has come to weave legal, ethical, economic, social and other demands into a coherent story. A vocabulary for the domain builds up, including special connotation of common words of which the outsider might not be aware.

How can there be understanding across different lifeworlds? This question is important in cross-cultural considerations in the Internet age, as well as between developers, users and domain experts in ISD. If all lifeworld meaning is socially constructed via language, it is possible in principle for there to be two lifeworlds that have almost no meaning or normativity in common. As alluded to above, however, Dooyeweerd (1955/1984) believed socially constructed norms and meanings to be concrete expressions of more fundamental meaning and normativity that transcends humanity. It is this that makes human living possible, including social construction itself, and of which there are distinct yet interrelated spheres or aspects. These aspects, therefore, are common to all lifeworlds and they present themselves to us in the lifeworld attitude, which Dooyeweerd listed informally in his opening paragraph above. He argued that the kernel meanings of aspects can never be grasped by theoretical thought but may be grasped intuitively. If Dooyeweerd is correct, then there might be two sides to the lifeworld: kernel meanings that are intuitively graspable across cultures, and specific meanings that are socially constructed within specific cultures (Basden \& Klein 2008). There are hints of this in Husserl (1954/1970,p.144) when he differentiated "objects ... as substrates of their properties" from "manners of appearance, or manners of givenness".

\section{LIFEWORLD-ORIENTED INFORMATION SYSTEMS DEVELOPMENT}


How, then, can we undertake, recognise or evaluate lifeworld-oriented information systems development (LOISD)? We may begin by saying that ISD is lifeworld-oriented to the extent that all relevant lifeworlds are respected and taken into account. Each lifeworld is likely to differ from others because of different background knowledge. Two main lifeworlds will be briefly considered with regard to the characteristics of the lifeworld outlined above, those of IS developer and of application domain (others could be considered in the same way).

\subsection{The Various Lifeworlds of ISD}

That in the lifeworld attitude we are closely engaged with the world draws attention to the engagements that IS developers make with their world. The everyday experience of ISD exhibits this engaged character rather than a distance that is characteristic of rational planning and legal relationships. This drives ISD towards closer engagement among team members, and between team members and those not organisationally in the team, such as users and domain experts. If the relationship between the developers and domain experts takes on a distal nature then the knowledge that is conveyed will be of poor quality, so the IS will not become 'trustable'. If the relationship between developers and users is distal then what the users really need will not become adequately known by the developers, so the IS will not become useful and 'saleable'. If inter-developer relationships are distal, such as mediated by deliverables that are signed off before being passed across to the next developer, then increased errors can be expected.

This might explain why agile development methods are providing greater productivity, lower rates of errors and greater programmer satisfaction. To the extent that it encourages such engagement, agile methods may be seen as a step towards LOISD.

From a lifeworld perspective as outlined above, ISD is usefully seen as human activity that exhibits multiple aspects. If we employ Dooyeweerd's suite of aspects as a categorization with which to approach this, then an investigation of the everyday life of ISD will find many aspects, if the case study above is not untypical. Basden (2008) did so, separating out the plethora of issues that are important in everyday ISD, finding that not only is every aspect exhibited, but that it is exhibited in several ways. ISD may be seen as a several multi-aspectual human activities interwoven with each other, each involving a different relationship, including at least:

- orchestration of the overall ISD project; relationships within the team and with clients;

- anticipation of use of the IS and planning for it; relationships with users;

- acquiring knowledge about the domain of application; relationships with experts;

- construction of the technical artifact; relationships with the technology.

The first and fourth are mainly linked to the lifeworld of the IS developers, while the second and third are linked to the lifeworld of the application domain, though they are also human activities of IS development.

\subsection{The Lifeworld of the IS Developer}

Table 2 gives examples of aspects of the overall ISD project. In column 1 is the name of each aspect (those in Dooyeweerd's introductory list above but some renamed), in column 2 is the kernel meaning of the aspect, so this table may be referred to for what each aspect covers. Column 3 shows is how this may be manifested in the overall ISD project. Column 4 shows some main issues emphasised by the methodologies and academic literature discussed above.

Table 2. Illustrates aspects of overall ISD project and team

\begin{tabular}{|l||c|c|c||}
\hline \multicolumn{1}{|c|}{ Aspect } & Meaning & Examples found in ISD project & As emphasised in IS literature \\
\hline \hline Quantitative & Discrete amount & Number in team & Relational data model (tuples) \\
\hline Spatial & Continuous space & Layout of team's office & - \\
\hline Kinematic & Movement & People movement & - \\
\hline Physical & Energy, matter & Power consumption & - \\
\hline Biotic & Life functions & Health of team members & - \\
\hline
\end{tabular}




\begin{tabular}{|c|c|c|c|}
\hline Sensitive & Feeling and response & Emotions in team & Reactive approaches \\
\hline Analytical & Distinctness & Clarity of objectives & $\begin{array}{c}\text { Linear approaches (clarity of } \\
\text { stages) }\end{array}$ \\
\hline Formative & $\begin{array}{l}\text { Construction, design, goals, } \\
\text { technique, technology }\end{array}$ & Project planning, team skills & \begin{tabular}{|c|} 
Boehm's Spiral model; \\
Kautz et al.'s diversity reduction \\
Soft Systems Methodology \\
problem-solving
\end{tabular} \\
\hline Lingual & Symbolic signification & Documentation, communication & $\begin{array}{c}\text { Kautz et al.'s knowledge } \\
\text { Iivari et al.'s Speech-Act } \\
\text { approach }\end{array}$ \\
\hline Social & Relationships and roles & Team structure, socializing & $\begin{array}{c}\text { Kautz et al.'s structure } \\
\text { Iivari et al.'s Interactionist } \\
\text { approach }\end{array}$ \\
\hline Economic & Management of scarce resources & $\begin{array}{l}\text { Budgets, deadlines, facilities, } \\
\text { expertise }\end{array}$ & $\begin{array}{c}\text { Linear methodologies } \\
\text { Iivari et al.'s PWP approach }\end{array}$ \\
\hline Aesthetic & $\begin{array}{l}\text { Harmony (as in music), } \\
\text { humour, enjoyment }\end{array}$ & $\begin{array}{l}\text { Orchestration of whole project; } \\
\text { fun or boredom of the project }\end{array}$ & - \\
\hline Juridical & Due, appropriateness & $\begin{array}{l}\text { Justice to team members or } \\
\text { otherwise; } \\
\text { Contract with client }\end{array}$ & $\begin{array}{c}\text { Hirschheim \& Klein's (1994) } \\
\text { emancipatory ISD } \\
\text { Iivari et al.'s Trades Union } \\
\text { approach }\end{array}$ \\
\hline Ethical & Self-giving love & $\begin{array}{l}\text { Attitude of generosity or self- } \\
\text { interest pervading team }\end{array}$ & 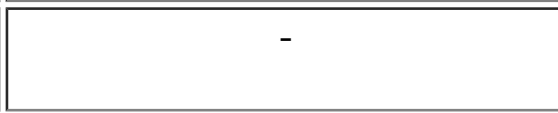 \\
\hline Faith & $\begin{array}{c}\text { Belief, vision, commitment, } \\
\text { morale }\end{array}$ & $\begin{array}{c}\text { Loyalty to project; } \\
\text { Religious faith of members }\end{array}$ & "SSM's Weltanschauung? \\
\hline
\end{tabular}

It may be seen that from the analytic aspect onwards, and possibly from the biotic, there is a difference between good and bad; these aspects are normative. Using the aspects in this way can provide methodological guidance for LOISD. Column 4 shows that each methodology or approach focuses on one or two aspects. This means each could be in danger of ignoring others unless positive action is taken to consider all aspects; this accounts for the tendency of both extant methodologies and IS research to ignore issues that might be important in everyday ISD.

Table 3 shows aspects of the other three human activities in ISD, starting at the analytic aspect. (Earlier aspects are largely as for the overall ISD project.)

Table 3. Some examples of aspects of three human activities in ISD

\begin{tabular}{|c|c|c|c|}
\hline Aspect & Anticipating Use & Knowledge acquisition & Creating the IS \\
\hline Analytical & Clarifying user requirements & 'Splitting up' aspects of domain & Deciding data types, classes \\
\hline Formative & Imagining future use & Structuring the knowledge & $\begin{array}{l}\text { Designing program architecture } \\
\text { and structures }\end{array}$ \\
\hline Lingual & Communicating with users & $\begin{array}{l}\text { Communicating with experts; } \\
\text { Drawing knowledge maps }\end{array}$ & $\begin{array}{l}\text { Writing the program; } \\
\text { Documentation }\end{array}$ \\
\hline Social & Respecting users & Close relationship with experts & Pair programming etc. \\
\hline Economic & $\begin{array}{l}\text { Need to understand future use } \\
\text { early on in project }\end{array}$ & Experts have limited time & $\begin{array}{l}\text { Efficiency of algorithms, data } \\
\text { storage, etc. }\end{array}$ \\
\hline Aesthetic & $\begin{array}{l}\text { Appreciating how IS will fit its } \\
\text { context of use; } \\
\text { Ensuring it is pleasant to use }\end{array}$ & $\begin{array}{l}\text { Seeing how all domain knowledge } \\
\text { works in harmony }\end{array}$ & $\begin{array}{l}\text { The fun and beauty of programs } \\
\text { (Knuth, 2001); } \\
\text { Style of user interface, web }\end{array}$ \\
\hline
\end{tabular}




\begin{tabular}{||l||l||l|l||} 
& & & pages. \\
\hline \hline Juridical & $\begin{array}{l}\text { Ensuring appropriateness of IS to } \\
\text { all stakeholders }\end{array}$ & $\begin{array}{l}\text { Doing justice to all (diverse) domain } \\
\text { knowledge }\end{array}$ & $\begin{array}{l}\text { Not cutting corners in building } \\
\text { the IS }\end{array}$ \\
\hline Ethical & Giving priority to users' ideas & Generous attitude to experts & $\begin{array}{l}\text { Going beyond duty to make the } \\
\text { IS better }\end{array}$ \\
\hline Faith & $\begin{array}{l}\text { Vision for why the IS will be } \\
\text { important in use }\end{array}$ & Critical trust of experts & $\begin{array}{l}\text { Commitment to getting program } \\
\text { right }\end{array}$ \\
\hline
\end{tabular}

Even though this is far from complete, this aspectual analysis paints a richer picture of ISD than is commonly seen. While some aspects are well-covered in existing approaches, many are not. That the aspects are spheres of law means that most of these entries are normative, and may be incorporated into methodological guidelines for each of the activities of LOISD. Future research could add aspectual rationality, functioning and possibility to the picture.

Such an approach must be taken with care. It would be tempting to treat the aspects as mere categories or simple norms and, though that might indeed provide a superior methodology, it would not be full LOISD. LOISD must take account that much lifeworld knowledge is taken for granted, and thus tends not to emerge during discussion. This can plague all the ISD activities, but especially knowledge acquisition. It can be useful, therefore, to take stock from time to time, to ask ourselves "Which aspects are being over-emphasised here, and which are being ignored?" It is often the case, for example, that the economic aspect is over-emphasised while the ethical aspect of self-giving is overlooked, partly because of the assumption of competition as a high norm of business. When such a realisation occurs action can be taken to give fuller consideration to the overlooked aspects.

The aspects should not be treated as simple categories, but rather as spheres or areas of meaning from the standpoints of which we can consider all the issues involved. For example, the juridical sphere of 'due' does not by itself tell us what is due to each entity with which we engage; what it does is strongly urge us to consider that, and, in conjunction with the ethical aspect, to give ourselves wholeheartedly to this consideration.

\subsection{The Lifeworld of the Application Domain}

The challenge for IS development is that in it (at least) two lifeworlds meet, those of the human activities of ISD discussed above, especially the activities of anticipating use and knowledge acquisition, and that of the domain of application. Both domain experts and users of the IS being developed are immersed in this domain. Rather than treat the lifeworlds of experts and users separately, it is useful to examine the lifeworld of the application domain as a whole.

IS developers function best when they have internalised lifeworlds of both ISD and the domain. It is usually assumed that developers will be expert at development and will learn something of the domain, but the reverse can happen: those already functioning in the domain can themselves become the IS developers. The author had one experience of this: a world-leading corrosion expert became an IS developer when he began building his own expert systems, under the author's guidance (Hines \& Basden, 1986; Basden \& Hines, 1986). That the domain expert could become an IS developer was made possible because the expert system used, 'Savoir', was very easy to understand while also being powerful and flexible, and also because of the good relationship of respect built up between the two people, as referred to above. Arguably it should be preferable and easier for a domain expert to learn ISD than an expert developer to internalise the domain lifeworld. There has been too little discussion of the domain experts or users undertaking their own ISD.

The more common way is that an expert in ISD learns something of the domain, about the structure of its knowledge from experts, and how the IS should be used from potential users. All too often, what they learn is restricted to the explicit knowledge of the application, such as objectives, processes and formal organisational relationships among those operating in the domain, and too sharp a division is maintained between experts and users. In LOISD, however, the IS developer must also intuitively grasp much of the lifeworld of the domain, which is shared by both experts and users. How can this be achieved without a 30-year apprenticeship in the domain? It is possible that sufficient may be grasped to ensure reasonable quality ISD if the following pertain for the developer: 
- The developer has a strong intuitive grasp of all the kernel meanings of the aspects, recognising that none can be reduced to the others in terms of their normative force or the ways they make things meaningful. If Dooyeweerd is correct, then these kernels are intuitively graspable across lifeworlds, and this can help mutual understanding with both users and experts.

- The developer expects all aspects to be active in the domain, in both positive and negative ways. Table 4 provides examples for the later aspects, including the types of practical question that might be asked during analysis.

- It can be helpful to identify the central, 'qualifying' aspect(s) of the domain and keep seeking to understand how all in the domain links back to these. A useful way to achieve this is to ask users or experts to nominate which aspects are most important. Then knowledge acquisition spreads out to all aspects as they see fit. This is the approach of Winfield's (2000) 'Multi-aspectual Knowledge Elicitation' process (Winfield \& Basden, 2006).

- The developer keeps looking for aspects of the lifeworld that have not yet been fully discussed, and giving users and experts the opportunity to express whatever might be meaningful in these.

- The developer has an attitude of respect for how all aspects make sense and are worked out in specific ways by those living in the domain, especially the concrete norms of the domain and what is deemed important.

When expert or user are themselves the developer, most of these questions still apply, and can be quite useful in stimulating self-critique in relation to the status quo.

Table 4. How aspects can separate out what is important in domain

\begin{tabular}{|c|c|c|}
\hline Aspect & What is important in domain & Useful questions to ask (examples) \\
\hline Analytical & $\begin{array}{l}\text { Distinctions important to domain; rationalities } \\
\text { of domain }\end{array}$ & $\begin{array}{l}\text { What are the main categories? What others are often } \\
\text { overlooked? }\end{array}$ \\
\hline Formative & Goals, techniques, technologies of domain & $\begin{array}{l}\text { What happens in this domain? } \\
\text { What techniques are used? }\end{array}$ \\
\hline Lingual & $\begin{array}{l}\text { Vocabulary and special connotations given to } \\
\text { common words }\end{array}$ & $\begin{array}{l}\text { What does this phrase mean? } \\
\text { What types of diagram or signs are there? }\end{array}$ \\
\hline Social & Social structures and relationships in domain & $\begin{array}{l}\text { How do roles X and Y relate to each other? } \\
\text { What institutions have authority here? }\end{array}$ \\
\hline Economic & Limitations coped with in the domain & $\begin{array}{l}\text { What resources is it most important to keep an eye on? } \\
\text { How are they managed? }\end{array}$ \\
\hline Aesthetic & $\begin{array}{l}\text { How the domain holds together; } \\
\text { Enjoyment of domain }\end{array}$ & $\begin{array}{l}\text { How does everything hold together? } \\
\text { What fun do you get? Tell me some jokes! }\end{array}$ \\
\hline Juridical & What is appropriate and proportional in domain & $\begin{array}{l}\text { What kinds of behaviour would be inappropriate? } \\
\text { Who are the main stakeholders, and what is due to } \\
\text { them? }\end{array}$ \\
\hline Ethical & Willingness to 'go the extra mile' & What is it about life in this domain that you love? \\
\hline Faith & Belief that the domain is important & $\begin{array}{l}\text { What does this contribute to humanity and history (in } \\
\text { the eyes of God)? }\end{array}$ \\
\hline
\end{tabular}

What this table tells us is that, even while the developer need not grasp the details of the domain, especially those of its science, s/he can and should grasp the overall shape the domain has in each aspect. Most knowledge acquisition or systems analysis texts emphasise the need to accurately understand the analytical and formative shape, but few extend to other aspects of its shape, from the aesthetics of the domain onwards. This table suggests that in LOISD the developer should proactively seek to understand the overall shape of the domain in every aspect. 
The kinds of questions shown in the table (suitably reworded according to situation) are ones that are likely to be reasonably understandable in all cultures, because they try to express the intuitively-grasped kernel meanings of the aspects that transcend cultures.

\section{CONCLUSION}

This paper has proposed a new approach to IS development: lifeworld-oriented IS development (LOISD). The aim is to provide a framework for understanding real-life ISD so that all the issues that might determine its quality and success or failure can be recognised, discussed and responded to. It is suggested that many extant methodologies and data models, and especially much academic literature on ISD, can be problematic because they restrict the developer's and researcher's view so that many important issues are treated as 'sediments' to be discarded rather than given the attention they deserve. To rectify this, LOISD takes full account of the lifeworlds of IS developer, users and domain experts - the highly diverse, taken-for-granted pools of knowledge that are active in everyday life of each of these. Though a number of the characteristics of the lifeworld (discussed above) may be detected in ISD methods, they have not previously been put together in the way outlined here.

Dooyeweerd's (1955/1984) notion of aspects as distinct spheres of meaning and law has been widely used here to conceptualise the diversity of the lifeworld, making it possible to paint a richer picture than hitherto available. Doing this separates out four distinct multi-aspectual human activities that constitute ISD, each exhibiting all the aspects: conducting the overall project, anticipating use, acquiring knowledge and constructing the IS. Dooyeweerd tentatively proposed a suite of aspects, which is arguably more suited than others are to our use here because it has been carefully thought-out and philosophically grounded.

Iivari et al. (1998) show that examining philosophical assumptions can differentiate ISD approaches. Table 5 shows the ontological, epistemological, ethical and methodological assumptions of LOISD based on Dooyeweerd, comparing them with those of the five ISDAs mentioned in Iivari et al. See Basden (2008) for explanation of Dooyeweerd's ideas.

Table 5. Philosophical assumptions of LOISD based on Dooyeweerd

\begin{tabular}{|c|c|c|}
\hline Assumption & As in Iivari et al. (1998) & Made by LOISD based on Dooyeweerd \\
\hline \begin{tabular}{|l|} 
View of data \\
/ information
\end{tabular} & Descriptive or constitutive & $\begin{array}{l}\text { An object of human lingual functioning, in which the whole diversity of } \\
\text { meaning may be expressed. }\end{array}$ \\
\hline View of IS & Technical or social system & Human living with I.T. \\
\hline $\begin{array}{l}\text { View of } \\
\text { human } \\
\text { beings }\end{array}$ & $\begin{array}{l}\text { Deterministic or } \\
\text { voluntaristic }\end{array}$ & $\begin{array}{l}\text { We function in all aspects all the time and in each we experience a } \\
\text { different kind of freedom and constraint. (Dooyeweerd's discussion of the } \\
\text { human ego is not relevant here.) }\end{array}$ \\
\hline \begin{tabular}{|l||} 
View of \\
(information) \\
technology
\end{tabular} & $\begin{array}{l}\text { Determining us, or a matter } \\
\text { of human choice }\end{array}$ & $\begin{array}{l}\text { Technology in general opens up the potential of the formative aspect; } \\
\text { Information technology opens up the potential of the lingual aspect; } \\
\text { In both cases, this should be done in service of all other aspects, and we } \\
\text { should not let it dominate us. See Basden (2010). }\end{array}$ \\
\hline \begin{tabular}{|l||} 
View of \\
Organisations
\end{tabular} & Structural or interactional & $\begin{array}{l}\text { Voluntary or involuntary associations in which roles and relationships are } \\
\text { important (Dooyeweerd, 1986). }\end{array}$ \\
\hline Epistemology & Positivist or anti-positivist & $\begin{array}{l}\text { The human knower as part of the knowable world; multi-aspectual ways } \\
\text { of knowing beyond the theoretical; intuition and everyday knowing; } \\
\text { reality as friendly rather than hostile to human knowing (contra Kant); } \\
\text { transcendental critique of theoretical thought. }\end{array}$ \\
\hline $\begin{array}{l}\text { Role of IS } \\
\text { science }\end{array}$ & $\begin{array}{l}\text { Means-end oriented or } \\
\text { interpretative }\end{array}$ & Disclosure of laws of lingual aspect in relation to all others. \\
\hline $\begin{array}{l}\text { Value of IS } \\
\text { research }\end{array}$ & \begin{tabular}{|l|} 
To assist communicational, \\
social, problem-solving, \\
justice or managerial
\end{tabular} & To enable technology-mediated lingual functioning to serve all aspects. \\
\hline
\end{tabular}




\begin{tabular}{||l||l||l||} 
& aspects & \\
\hline \hline $\begin{array}{l}\text { IS research } \\
\text { methodology }\end{array}$ & $\begin{array}{l}\text { Case studies, action } \\
\text { research, conceptual } \\
\text { development, technical } \\
\text { development or formal } \\
\text { analysis }\end{array}$ & Any of these; it is attitude that is important. \\
\hline
\end{tabular}

Though it is not appropriate to elaborate further on the entries in this table here, it is intended that a paper will be forthcoming that does this. Two things however may be noted for further discussion. One is that though Iivari et al.'s discussion of most assumptions is dualistic, their discussion of the value of IS research is not dualistic but prefigures a Dooyeweerdian discussion; this may be because 'value' presupposes meaning and normativity, both of which are central to Dooyeweerd's notion of aspects. This suggests that Iivari et al.'s approach might be commensurate with a Dooyeweerdian one. The second is to suggest it might be important to discuss additional things about which philosophical assumptions are made than those included by Iivari et al., such as the nature of the world in which IS are situated, the nature of diversity and coherence, and the long-term destiny of humanity and technology.

The notion of aspects as spheres of meaning and law that make all human (and other) functioning possible provides us with the interesting idea that the lifeworld has two sides. The fact-side lifeworld is socially-constructed knowledge of all that has occurred or exists, including social norms, and this differs between different cultural groups. By contrast, the law-side lifeworld transcends cultural groups and is constituted of the kernel meanings of the aspects, which are intuitively grasped. This offers a way in which people from different lifeworlds (such as IS developers, users, domain experts) can understand each other; a set of example questions, based on this, is offered that might assist communication between IS developers and those involved in the application domain.

LOISD might also narrow the gulf between the practice of ISD and academic discussion thereof. A lifeworld-oriented approach could provide a ground on which a number of extant debates in the ISD community can take place. For example, the debate between Kautz et al. (2007a,b) and Baskerville et al. (2007) over whether agile methods are fundamentally different from traditional ones may be conducted as follows. The difference between methods is likely to be more evident in certain of the multi-aspectual human activities than in others, especially those relating to the overall project and to creation of the IS. This might help to focus the discussion. Reference to the aspects can then help to separate out the ways in which the difference might be particularly salient, such as social (team structure), formative (planning), lingual (type of documentation) and aesthetic (fun). Then what is taken for granted by each culture in each aspect might be debated, differentiating between fact-side and law-side lifeworlds.

LOISD is a new idea, so it may be too early to know what its advantages and drawbacks might be, whether based on Dooyeweerd or not. It could require more effort, especially in handling a wider range of factors. Unless care is taken, ISD could become characterized by slot-filling - addressing each aspect of each ISD activity once, and then moving on to the next. That would be a travesty of LOISD, because aspects are not mere categories but are spheres of meaning that should be used to stimulate human thinking. Dooyeweerd maintained that the kernel meanings of the aspects are grasped by our intuition, which should make the aspects easy to use during the flow of thinking that characterizes ISD and other analysis. This is indeed what the author has experienced, and thinking aspectually tends to become secondnature. It is especially useful in sensitizing the analyst to what is being overlooked and to tacit knowledge.

Perhaps the biggest danger of LOISD is that its focus on shared background knowledge might lead to upholding the status quo when it should be challenged. This danger is more pronounced when most attention is given to what we called the fact-side of the lifeworld, which is background knowledge of the structures, things, histories, and sociallyconstructed norms of the domain and of the ISD process. When attention is given to the law-side lifeworld, however, then new possibilities might be more readily brought to attention. This is because the aspects as spheres of law define broad types of possibility, each of which is irreducible to other types. For example, the juridical aspect tells us that 'what is due' or 'appropriate' is an important sphere of meaning to consider, leaving open the possibility that current legal structures, developed from earlier eras, hinder this and therefore should be radically changed. The use of aspects as aids to such out-of-the-box thinking has yet to be properly researched.

The above might seem a rather developer-centric view of ISD, rather than user-centred. That would be a mistaken 
impression because 'user-centred' does not mean the developer merely responds to what the user wants. Instead, LOISD evokes a responsibility that looks outward not only to the user as such but to the user who is immersed in the domain of application, and beyond the user to the lifeworld of the domain, and even beyond that to the wider world of which it is part.

Dooyeweerd's aspects should not be seen as providing answers to the question "What should I do in LOISD?" nor even as providing questions to ask, though some examples questions have been offered above. Rather, the aspects enable us to formulate areas of discussion, and in this way to encourage free yet meaningful engagement and mutual respect between developers, users and experts. As mentioned above, mutual understanding might be enhanced by reference to the intuitively-grasped kernel meanings of aspects.

LOISD welcomes diversity, rather than reducing it as Kautz et al. (2007a) sought to do, and recognises importance of taken-for-granted knowledge as well as that which is 'negotiated'. Seeing LOISD as several interwoven multi-aspectual human activities, allows an holistic view in which the different factors are nevertheless clearly distinguished. LOISD can be likened to a symphony, in which all the instruments of the orchestra play their part and are essential to the whole. Bringing such orchestration to ISD is what lifeworld-oriented information systems development hopes to achieve.

\section{REFERENCES}

Attarwala, F.T. \& Basden, A. (1985). A methodology for constructing Expert Systems. R\&D Management, 15(2), p.141-149.

Basden, A. (2008). Philosophical Frameworks for Understanding Information Systems. IGI Global, Hershey, PA, USA.

Basden, A. (2010) On Using Spheres of Meaning to Define and Dignify the IS Discipline. International Journal of Information Management, February 2010.

Basden, A., Hines, J. G. (1986). Implications of the relation between information and knowledge in use of computers to handle corrosion knowledge. British Corrosion Journal, v.21, n.3, p.157-162.

Basden, A., \& Klein, H.K. (2008). New research directions for data and knowledge engineering: A philosophy of language approach. Data \& Knowledge Engineering, 67, 2, 260-285.

Basden, A., Watson, I.D., Brandon, P.S. (1995) Client-Centred: An Approach to Knowledge Based Systems. CLRC: Rutherford Appleton Laboratory, U.K. ISBN 0902376357.

Baskerville, R, Pries-Heje, J., Ramesh, Balasubramaniam. (2007). Information Systems Journal, 17, 241-245.

Beck, K. (2000). Extreme programming explained: Embrace change. Boston: Addison-Wesley.

Bergvall-Kåreborn B, Mirijamdotter A, Basden A. (2004) Basic principles of SSM Modeling: An examination of CATWOE from a soft perspective. Systemic Practice and Action Research, 17(2), p.55-73.

Boehm, B. W. (1988, May). A spiral model of software development and enhancement. IEEE Computer, 21(5), 61-72.

Booch G, (1991), "Object Oriented Design, with applications", The Benjamin/Cummings Publishing Company, Redwood City, California, USA.

Brandon, P. S., Basden, A., Hamilton, I., \& Stockley, J. (1988). Application of expert systems to quantity surveying. London: Royal Institution of Chartered Surveyors.

Bunge, M. (1979). Treatise on basic philosophy, Vol. 4: Ontology 2: A world of systems. Boston: Reidal. 
Burrell, B., Morgan, G. (1979). Sociological Paradigms and Organisational Analysis London: Heinemann.

Castell, A. C., Basden, A., Erdos, G., Barrows, P., \& Brandon, P. S. (1992). Knowledge based systems in use: A case study. In British Computer Society Specialist Group for Knowledge Based Systems, Proceedings from Expert Systems 92 (Applications Stream). Swindon, England: British Computer Society.

Checkland P, (1999). Soft Systems Methodology: a 30-year retrospective, in Systems Thinking, Systems Practice includes a 30-year retrospective, Wiley, New York.

Chen, P.P. (1976). The entity-relationship model - towards a unified view of data. ACM Trans Database Syst., v.1, n.1, pp.9-36.

Clouser, R. (2005). The Myth of Religious Neutrality; An Essay on the Hidden Role of Religious Belief in Theories. University of Notre Dame Press, Notre Dame, Indiana, USA.

Codd, E. A. (1970). A relational model for large shared databanks. Communications of the ACM, 13(6), 377-387.

Dooyeweerd, H. (1955/1984). A New Critique of Theoretical Thought, Vol. I-IV. 1975 edition. Paideia Press, Jordan Station, Ontario.

Dooyeweerd, H., (1986). A Christian Theory of Social Institutions, tr. M. Verbrugge. The Herman Dooyeweerd Foundation, La Jolla, Ca, USA.

Gadamer, H-G. (1977). Philosophical Hermeneutics. tr. D.E. Linge. University of California Press, Los Angeles, USA.

Gamma, E., Helm, R., Johnson, R., \& Vlissides, J. (1995). Design patterns: Elements of reusable object-oriented software. Reading, MA: Addison-Wesley.

Habermas, J. (1986). The theory of communicative action: Volume 1, Reason and the rationalization of society (T. McCarthy, Trans.). Cambridge, England: Polity Press.

Habermas, J. (1987). The Theory of Communicative Action: Volume 2, The Critique of Functionalist Reason. tr. T.McCarthy. Polity Press, Cambridge, UK.

Hartmann, N. (1952). The new ways of ontology. Chicago: Chicago University Press.

Heidegger, M. (1927/1962). Being and Time. tr. J. Macquarrie, B. Robinson. Blackwell Publishing, Oxford, UK.

Hines, J. G., \& Basden, A. (1986). Experience with use of computers to handle corrosion knowledge. British Corrosion Journal, 21(3), 151-156.

Hirschheim, R., \& Klein, H. K. (1994). Realizing emancipatory principles in information systems development: The case for ETHICS. MIS Quarterly, 18(1), 85-109.

Hirschhein, R., Klein, H.K., Lyytinen, K. (1995). Information Systems Development and Data Modelling: Conceptual and Philosophical Foundations. Cambridge University Press.

Honneth, A., Knodler-Bunte, E., Windmann, A. (1981). "The Dialectics of Rationalization: an interview with Jürgen Habermas", Telos, 49, 3-31.

Husserl, E. (1954/1970). The Crisis of European Sciences and Transcendental Phenomenology. Northwestern University Press, Evanston, Illinois, USA.

Iivari, J., Hirschheim, R., Klein, H.K. (1998), A Paradigmatic Analysis of Contemporary Schools of IS Development Approaches and Methodologies. Information Systems Research, Vol.9, No.2, p. 164-193. 
Kautz, K., Madson, S., Nørbjerg, J. (2007a). Persistent problems and practices in information systems development. Information Systems Journal, 17, 217-239.

Kautz, K., Madson, S., Nørbjerg, J. (2007b). Continuing the debate: a response to a response - persistent problems and practices in information systems development as enduring contradictions of new software development approaches. Information Systems Journal, 17, 247-249.

Knuth, D. (2001). Things a computer scientist rarely talks about. Stanford, CA: CSLI.

Maslow, A. (1943). A theory of human motivation. Psychological Review, 50, 370-396.

Polanyi, M. (1967). The Tacit Dimension. Routledge \& Kegan Paul, London.

Probert, S.K. (1997) The metaphysical assumptions of the (main) soft systems methodology advocates in Winder, R.L., Probert, S.K., Beeson, I.A. Philosophical Aspects of Information Systems, Taylor and Francis.

Royce, W.W. (1970). Managing the development of large software systems: concepts and techniques. Proc. IEEE, Wescon, p.328-339.

Schutz, A. \& T. Luckmann. (1973). Structures of the Life-World, Volume I. Northwestern University Press, Evanston, Illinois, USA.

Wenger, E. (1998). Communities of Practice. Cambridge University Press.

Winfield, M. (2000). Multi-Aspectual Knowledge Elicitation. PhD Thesis, University of Salford, U.K.

Winfield, M.J. \& Basden, A. (2006). Elicitation of highly interdisciplinary knowledge. pp. 63-78 in S. Strijbos, A. Basden (eds.) In Search of an Integrated Vision for Technology; Interdisciplinary Studies in Information Systems. Springer. 